\title{
Consulting Physician
}

National Cancer Institute

\section{Source}

National Cancer Institute. Consulting Physician. NCI Thesaurus. Code C51815.

A physician that has expertise in a specific medical disciple that can offer expertise or advice to other physicians and healthcare providers. 